\title{
Neuroendocrine carcinoma of the common bile duct associated with congenital bile duct dilatation: a case report
}

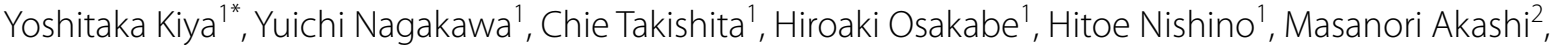 \\ Hiroshi Yamaguchi ${ }^{3}$, Toshitaka Nagao ${ }^{4}$, Ryo Oono ${ }^{5}$, Kenji Katsumata ${ }^{1}$ and Akihiko Tsuchida ${ }^{1}$
}

\begin{abstract}
Background: Cholangiocarcinoma is frequently observed in patients with congenital bile duct dilatation (CBDD). Most cholangiocarcinomas are adenocarcinomas. Other types, especially neuroendocrine carcinomas (NECs), are rare. To the best of our knowledge, this is the third reported case of an NEC of the common bile duct associated with CBDD and the first to receive adjuvant chemotherapy for advanced disease.
\end{abstract}

Case presentation: A 29-year-old woman presented with upper abdominal pain. Preoperative imaging indicated marked dilatation of the common bile duct and a tumor in the middle portion of the common bile duct. She was suspected of having distal cholangiocarcinoma associated with CBDD and underwent pylorus-preserving pancreaticoduodenectomy. Pathological and immunohistological findings led to a final diagnosis of large-cell NEC (pT3aN1M0 pStagelIB). The postoperative course was uneventful, and she was administered cisplatin and irinotecan every 4 weeks (four cycles) as adjuvant chemotherapy. She has remained recurrence-free for 16 months.

Conclusions: NEC might be a differential diagnosis in cases of cholangial tumor associated with congenital bile duct dilatation. This presentation is rare and valuable, and to establish better treatment for NEC, further reports are necessary.

Keywords: Neuroendocrine carcinoma, Congenital bile duct dilatation, Cholangiocarcinoma, Large cell neuroendocrine carcinoma, Adjuvant chemotherapy, Case report

\section{Background}

Congenital bile duct dilatation (CBDD) is found in approximately one in 100,000 to 150,000 people, and is frequently observed in Asian patients, including those of Japanese origin [1]. In Japanese patients with CBDD, the incidence of cholangiocarcinoma is approximately $15 \%$. The incidence of cholangiocarcinoma after extrahepatic bile duct excision is $0.7 \%$, which is approximately 200 times higher than the incidence of cholangiocarcinoma in the general population in Japan [2, 3]. Cholangiocarcinomas frequently develop in patients with CBDD and are usually adenocarcinomas; other types, especially neuroendocrine carcinomas (NEC), are rare [4].

We present a rare case of an NEC of the common bile duct associated with CBDD. To the best of our knowledge, this is the third case of an NEC of the common bile duct associated with CBDD to be reported $[5,6]$.

\footnotetext{
*Correspondence: yoshitakakiya@gmail.com

1 Department of Gastrointestinal and Pediatric Surgery, Tokyo Medical

University, 6-7-1 Nishi-shinjuku, Shinjuku- ku, Tokyo 160-0023, Japan

Full list of author information is available at the end of the article
}

(c) The Author(s) 2021. This article is licensed under a Creative Commons Attribution 4.0 International License, which permits use, sharing, adaptation, distribution and reproduction in any medium or format, as long as you give appropriate credit to the original author(s) and the source, provide a link to the Creative Commons licence, and indicate if changes were made. The images or other third party material in this article are included in the article's Creative Commons licence, unless indicated otherwise in a credit line to the material. If material is not included in the article's Creative Commons licence and your intended use is not permitted by statutory regulation or exceeds the permitted use, you will need to obtain permission directly from the copyright holder. To view a copy of this licence, visit http://creativecommons.org/licenses/by/4.0/. The Creative Commons Public Domain Dedication waiver (http://creativecommons.org/publicdomain/zero/1.0/) applies to the data made available in this article, unless otherwise stated in a credit line to the data. 


\section{Case presentation}

A 29-year-old Japanese woman, with a history of cholecystitis at the age of 15 years and no relevant family history, presented to a hospital complaining of upper abdominal pain, which began to worsen one month ago.

The patient's vital signs were stable. Physical examination revealed slight upper abdominal tenderness, without jaundice, and a positive Murphy's sign and Blumberg's sign.

Blood analysis revealed elevated levels of aspartate aminotransaminase, $309 \mathrm{IU} / \mathrm{L}$ (normal, 8-40 IU/L); alanine aminophosphatase, $511 \mathrm{IU} / \mathrm{L}$ (normal, 5-35 IU/L); $\gamma$-glutamyl transpeptidase, 614 IU/L (normal, 7-50 IU/L); alkaline phosphatase, $822 \mathrm{IU} / \mathrm{L}$ (normal, 100-340 $\mathrm{IU} / \mathrm{L}$ ); and carcinoembryonic antigen, $79.7 \mathrm{ng} / \mathrm{mL}$ (normal, $0-4.9 \mathrm{ng} / \mathrm{mL}$ ). All other laboratory data were within normal limits. The levels of hepatobiliary enzymes and tumor markers were elevated, which implied that the patient might have developed cholangitis due to a cholangial carcinoma.

Abdominal dynamic contrast-enhanced computed tomography (CECT) showed dilatation of the common bile duct and the bilateral intrahepatic bile ducts (which was diagnosed as Todani type IV-A) and a tumor in the middle portion of the common bile duct (Fig. 1a, b). Endoscopic ultrasonography and magnetic resonance cholangiopancreatography showed a tumor in the cystic dilated common bile duct (Fig. 1c, 1d); additionally, one centimeter of the common channel continued from the duodenal papilla (Fig. 1e, f), and no evidence of choledocholithiasis was observed. Considering all factors, since cholangial carcinoma was highly suspected, endoscopic retrograde cholangiopancreatography and peroral cholangioscopy were not performed to prevent pancreatitis.

The patient was suspected of having distal cholangiocarcinoma (cT2NOMO cStageIB) associated with CBDD and underwent pylorus-preserving pancreaticoduodenectomy with modified Child reconstruction. Intraoperative observation of the abdominal cavity did not reveal any feature of tumor dissemination or liver metastasis. The surgery was performed as scheduled.

The final diagnosis was large-cell NEC (pT3aN1M0 pStageIIB), and the resection margin was negative. Macroscopic findings showed a 50-mm sessile irregular lesion protruding into the markedly dilated lower common bile duct (Fig. 2a, b). Pathological findings showed solid proliferation of large, atypical cells accompanied by an adenocarcinomatous component (less than $5 \%$ ); i.e. the transition area of these component (Fig. 3a), and large tumor cells with irregular-shaped hyperchromatic nuclei (Fig. 3b). Metastasis was detected in one of the 31 lymph nodes tested. Immunohistochemical studies revealed that the large, atypical cells were positive for AE1/AE3,
E-cadherin, CD56, chromogranin A, and synaptophysin. The Ki-67 labeling index was over $90 \%$ in the solid component (Fig. 3c, d).

The postoperative course was uneventful, and she was discharged on the 14th postoperative day. This was a case of an advanced NEC, and she was scheduled to receive adjuvant chemotherapy to prevent recurrence. However, the standard regimen of adjuvant chemotherapy for neuroendocrine cholangiocarcinoma has not yet been established; therefore, we selected a mixed regimen of cisplatin and irinotecan according to the National Comprehensive Cancer Network (NCCN) guidelines for small cell carcinomas of the lung. The patient received cisplatin at a dose of $60 \mathrm{mg} / \mathrm{m}^{2}$ on the 1st day and irinotecan at $60 \mathrm{mg} / \mathrm{m}^{2}$ on the $1 \mathrm{st}, 8$ th, and 15 th days. This regimen was repeated every 4 weeks for four cycles as adjuvant chemotherapy. She has been recurrence-free for over 16 months.

\section{Discussion and conclusions}

The most common form of cholangiocarcinoma associated with CBDD is adenocarcinoma; NECs are rare, and only two cases have been reported in the English literature (Table 1). Pathological diagnoses of the previously reported cases were of early well-differentiated NECs [5, 6]. This is the third case of an NEC of the common bile duct associated with CBDD and the first case to receive adjuvant chemotherapy for advanced disease.

CBDD is observed more often in female patients than in male patients (male-to-female ratio, 1:3). Similarly, CBDD is common in Asian patients. Todani et al., categorized CBDD into five main types, and almost all CBDDs of types Ia, Ic, and IV-A are associated with pancreaticobiliary maljunction [2].

A proposed etiology of bile duct dilatation is an increase in the bile duct pressure of the narrow segment of the lower bile duct accompanied by pancreaticobiliary maljunction while the bile duct wall is immature, thereby resulting in the dilation of the bile duct. Another hypothesis is that the primitive common bile duct proliferates asymmetrically in the early embryonic period; this implies that insufficient epithelial proliferation in the lower bile duct and excessive proliferation in the upper bile duct lead to stenosis of the lower bile duct and dilatation of the upper bile duct [2].

Pancreaticobiliary maljunction causes mixing and regurgitation of bile and pancreatic juices, which stagnate in the gallbladder and the bile duct, especially in the dilated common bile duct. This increases the cytotoxic potential for damage to the biliary epithelium under conditions of infection, inflammation, biliary stasis, decreased trypsin inhibitor concentrations, and the presence of enterokinase $[5,7,8]$. During repair, multiple 

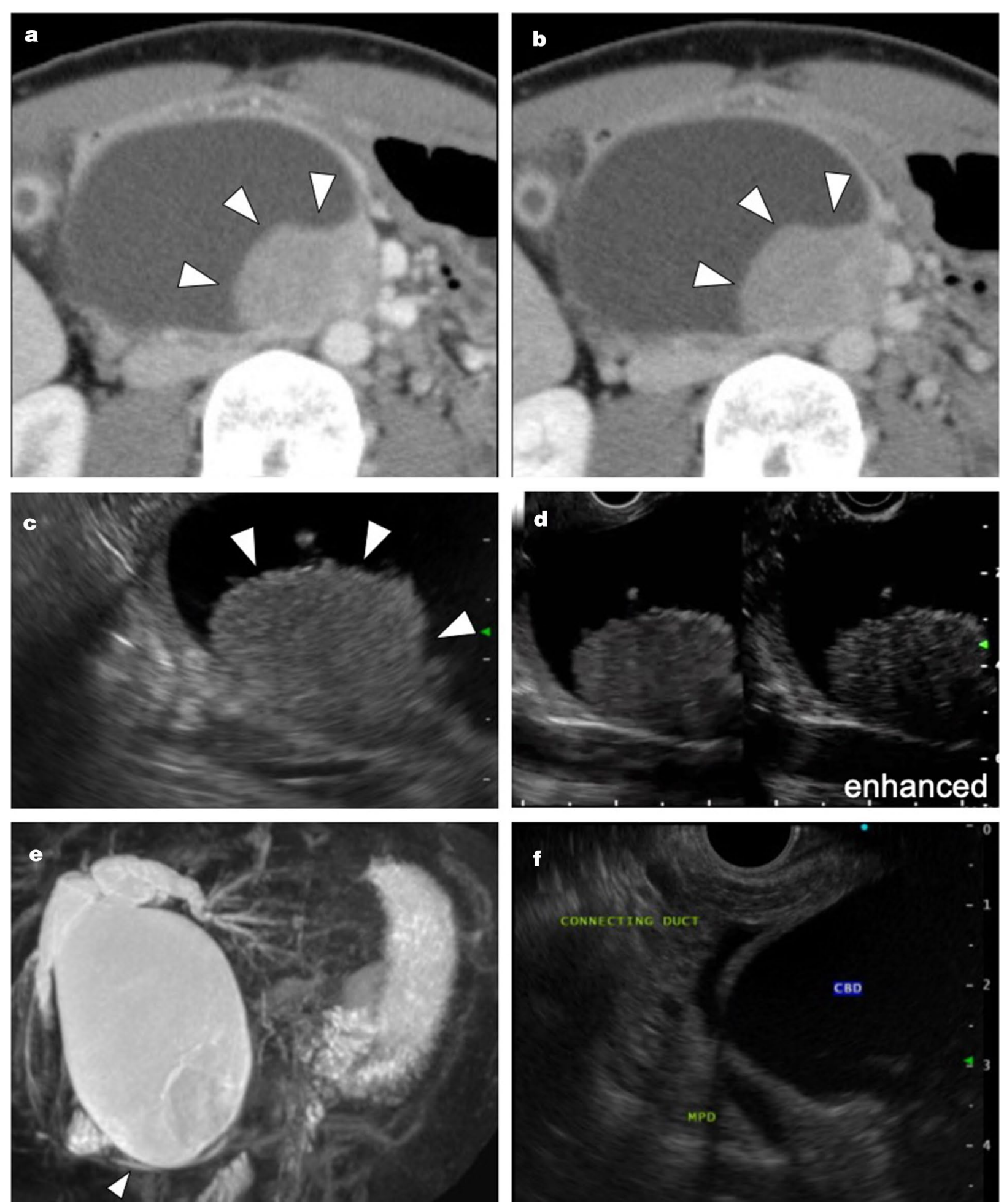

Fig. 1 Preoperative imaging. a, b Arterial phase and delayed phase of abdominal dynamic contrast-enhanced computed tomography. These images show a tumor (arrowhead) in the middle portion of the common bile duct and dilatation of the common bile duct and the intrahepatic bile ducts bilaterally; the dilatation is diagnosed as Todani type IV-A. The tumor has enhanced iso-density at the arterial phase, and contrast effect was prolonged to the delayed phase. c Endoscopic ultrasonography shows a tumor (arrowhead) in the cystic dilated common bile duct. $\mathbf{d}$ Contrast-enhanced endoscopic ultrasonography shows the uptake of the contrast agent into the tumor. $\mathbf{e}$, $\mathbf{f}$ Magnetic resonance cholangiopancreatography and endoscopic ultrasonography show one centimeter of the common channel (arrowhead), which continued from the duodenal papilla 

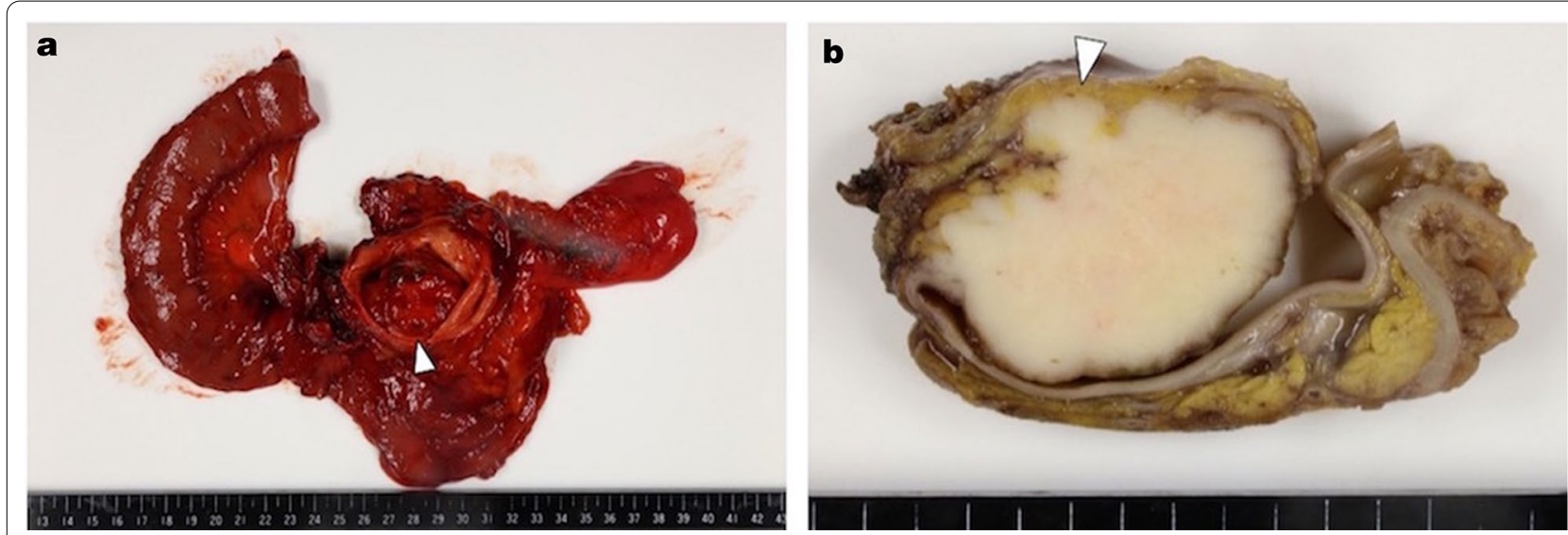

Fig. 2 Macroscopic finding. a A 50-mm sessile irregular lesion (arrowhead) protruding into the lower common bile duct is observed. b Gross description of the short axis of the common bile duct. Tumor invasion into the pancreas (arrowhead)
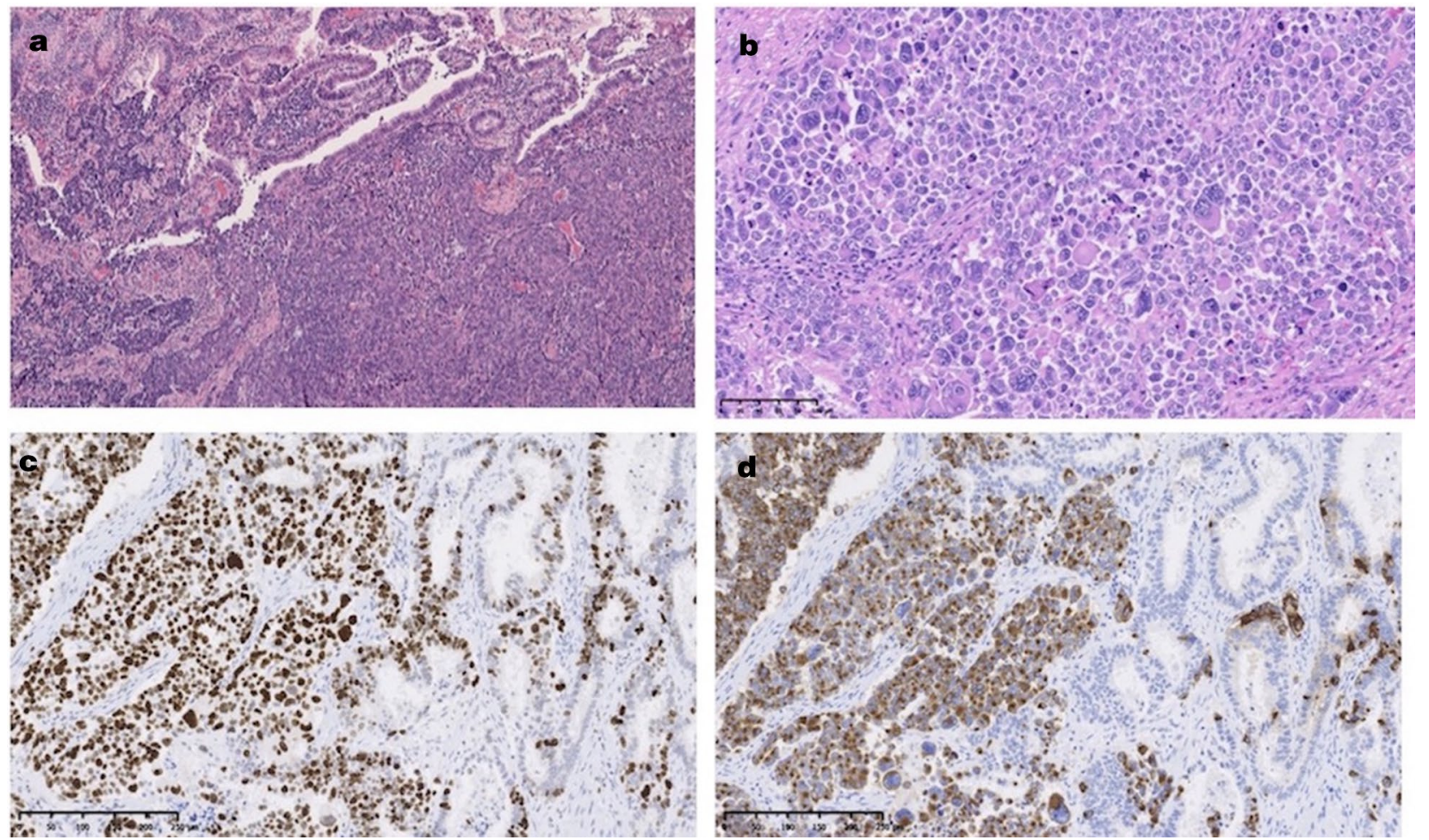

Fig. 3 Microscopic findings; hematoxylin and eosin stain and immunohistochemical stain. a The transition area from the adenocarcinoma with a tubulopapillary structure (left upper part) to the neuroendocrine carcinoma (NEC) with a solid structure (right lower part). Hematoxylin and eosin stain $(H \& E, \times 60)$. $\mathbf{b}$ The area of NEC consisting of large tumor cells with irregular-shaped hyperchromatic nuclei $(H \& E, \times 200)$. c Ki-67 labeling index was over $90 \%$ solid component $(\times 100)$. d Tumor cells are positive for chromogranin-A in the solid component, thereby revealing neuroendocrine differentiation $(\times 100)$

alterations of oncogenes and tumor suppressor genes occur, and this could lead to the development of carcinomas through multistage interactions. Hyperplasia of the biliary or gallbladder epithelium is a characteristic of pancreaticobiliary maljunction; moreover, mutations of the $K$-ras and $p 53$ genes and overexpression of the p53 protein are observed in malignant and benign lesions of the biliary tract in patients with pancreaticobiliary maljunction. These changes are referred to as the "hyperplasia-dysplasia-carcinoma sequence" $[9,10]$. 
Table 1 Case reports of neuroendocrine carcinomas of the common bile duct associated with congenital bile duct dilatation

\begin{tabular}{lllllll}
\hline Case & Author & Age/sex & Todani type & Diagnosis & Treatment & Prognosis \\
\hline 1 & Tonnhofer & 6/F & I & $\begin{array}{l}\text { Well-differentiated } \\
\text { neuroendocine carcinoma }\end{array}$ & Total extrahepatic bile duct resection & $\begin{array}{l}\text { no evidence of recurrence } \\
2 y\end{array}$ \\
2 & Takahashi & 28/F & IV-A & $\begin{array}{l}\text { Well-differentiated } \\
\text { neuroendocine carcinoma }\end{array}$ & $\begin{array}{l}\text { Total extrahepatic bile duct resection } \\
\text { Pancreaticoduodenectomy }\end{array}$ & $\begin{array}{l}\text { no evidence of recurrence } \\
3 y\end{array}$ \\
3 & Present case & 29/F & IV-A & $\begin{array}{l}\text { Poorly-differentiated } \\
\text { neuroendocine carcinoma }\end{array}$ & $\begin{array}{l}\text { Pylorus-preserving pancreaticoduodenectomy } \\
\text { Adjuvant chemotherapy evidence of recurrence } \\
\text { no }\end{array}$ & 16mo \\
\hline
\end{tabular}

In many anatomical sites, neoplasms that exhibit both neuroendocrine and non-neuroendocrine elements exist, which can be present as morphologically distinct or more intimately intermixed cell populations. The neuroendocrine elements of these "mixed" or "combined" neoplasms are most commonly NECs; the non-neuroendocrine components can be glandular, squamous, or of other lineages [11].

In our case, neuroendocrine components occupied $90 \%$ or more of the tumor's invasive area, and a few adenocarcinomatous components were observed (Fig. 4a). In contrast, early adenocarcinomatous components were observed on the mucosa of the tumor surface (Fig. 4b). This suggests that hyperplasia and dysplasia due to chronic inflammation of the bile duct mucosa initially result in adenocarcinomas, which subsequently transform to NECs (Fig. 3a); however, in our case, hyperplasia or dysplasia was slightly noted on the noncancerous mucosa of the bile duct or gallbladder, differing from typical CBDD. However, the concept of cancer stem cells is widely accepted as important in cancer development, with recent studies showing that cancer stem cells play important roles in the carcinogenesis of various types of cancer. Several investigations have demonstrated that although the different components of mixed neuroendocrine-non-neuroendocrine neoplasms are monoclonal, their molecular signature is not identical to that of their relative counterparts when they present as separate neoplasms $[12,13]$.

In our case, it was probable that the adenocarcinoma first developed in the common bile duct with subsequent neuroendocrine differentiation. In contrast, the two previous reports of NEC-associated CBDD did not clearly indicate whether their tumor included adenocarcinoma components; thus, NEC may have developed de novo in the common bile duct.

One study reported that the incidence of cholangiocarcinoma was approximately $15 \%$ in Japanese patients with CBDD [2,3]. Another study reported that the overall incidence of cholangiocarcinoma with pancreaticobiliary maljunction, with both a dilated and a nondilated bile duct, is $10.4 \%$, which is more than 285 times higher than the risk in the general population [10]. The average age of patients with cholangiocarcinoma associated with pancreaticobiliary maljunction is 10 years lower than that of the general population $[2,14,15]$.

Biliary NEC represents $0.19 \%$ of all primary malignant tumors in the extrahepatic bile duct [16]. It is estimated that over $50 \%$ of patients with gastroenteropancreatic NEC exhibit distant metastasis during initial diagnosis. Biliary NEC is relatively aggressive. In a review of 22 patients with biliary NEC, distant metastasis occurred
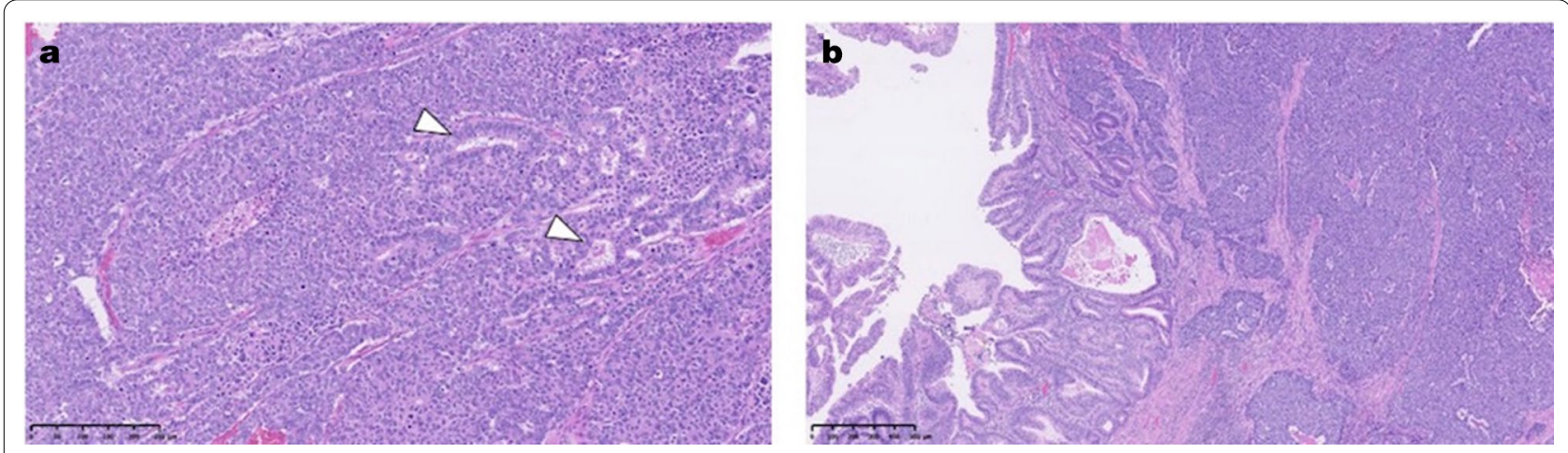

Fig. 4 Microscopic findings; neuroendocrine components and adenocarcinomatous components. a Neuroendocrine components occupy $90 \%$ or more of the tumor invasive area, and a few adenocarcinoma components are observed (arrowhead) $(\mathrm{H \& E}, \times 100)$. b Early adenocarcinoma components spread on the mucosa of the tumor surface $(H \& E, \times 40)$ 
in 16 cases on initial admission. Distant metastasis is present in all cases within one year after surgery, even though surgery is the mainstay of treatment for biliary NEC and is regarded as the curative option. The survival outcomes are poorer (in the decreasing order) for NECs that originate from the lungs, gastrointestinal tracts, and hepato-biliary-pancreatic systems [17]. Terashima et al., reported that the response rate to chemotherapy in patients with extrapulmonary NEC was lower than that in patients with pulmonary NEC. In cases of extrapulmonary NEC, the hepato-biliary-pancreatic systems group showed the lowest response rate [18]. In this case, preoperative imaging showed no distant metastasis, and the resection margin was negative. Furthermore, the disease has not recurred in this patient for over 16 months after surgery, which implies that this case is rare and valuable. Additionally, considering that distant metastasis within one year after surgery has been previously reported, adjuvant chemotherapy is important to prevent tumor recurrence. Recently, several investigations have reported the efficacy of immunotherapy for neuroendocrine neoplasms, which might become a novel therapy for advanced neuroendocrine tumors [19-25].

We present a rare case of a poorly differentiated NEC of the common bile duct associated with CBDD. Although the association between CBDD and NEC is unclear, CBDD is a known risk factor for carcinogenesis. As mentioned above, chronic inflammation results in adenocarcinoma, which transforms into neuroendocrine NECs. Thus, NEC should be considered a differential diagnosis for patients with cholangial tumors associated with CBDD. Although NECs generally have poor prognoses, no recurrence lesion was observed after surgery in this case, and the patient had a good course. Novel drugs, such as molecular-targeted drugs and immune checkpoint inhibitors, have been used for cancer; in the future, patients with biliary NEC might have a good prognosis, as in this case. To establish a more effective treatment, it is necessary to continue to accumulate similar reports.

\section{Abbreviations}

CBDD: Congenital bile duct dilatation; NEC: Neuroendocrine carcinoma.

\section{Acknowledgements}

Not applicable.

\begin{abstract}
Authors' contributions
$\mathrm{KY}$ and TA made substantial contributions to the conception and design of the study and to data acquisition, analysis, and interpretation. $\mathrm{KY}$ and TA drafted the article and made critical revisions related to important intellectual content of the manuscript. $\mathrm{NY}, \mathrm{TC}, \mathrm{OH}, \mathrm{NH}, \mathrm{AM}, \mathrm{YH}, \mathrm{NT}, \mathrm{OR}$, and $\mathrm{KK}$ contributed to data acquisition, analysis, and interpretation. All authors approved the final version of the manuscript for submission.
\end{abstract}

\section{Funding}

No external funding sources were used for this study.
Availability of data and materials

Not applicable.

\section{Declarations}

Ethics approval and consent to participate

Not applicable.

\section{Consent for publication \\ Written informed consent was obtained from the patient for publication of this case report and accompanying images.}

\section{Competing interests}

The authors declare that they have no competing interests.

\section{Author details}

'Department of Gastrointestinal and Pediatric Surgery, Tokyo Medical University, 6-7-1 Nishi-shinjuku, Shinjuku- ku, Tokyo 160-0023, Japan. ${ }^{2}$ Department of Surgery, Kurume University School of Medicine, 67 Asahicho, 830-0011 Kurume, Fukuoka, Japan. ${ }^{3}$ Department of Pathology, Saitama Medical University, 38 Morohongo, Moroyama-machi, Iruma-gun, Saitama 350-0495, Japan. ${ }^{4}$ Department of Anatomical Pathology, Tokyo Medical University, 6-7-1 Nishi-shinjuku, Shinjuku-ku, Tokyo 160- 0023, Japan. ${ }^{5}$ Department of Digestive Surgery, Nitobe Memorial Nakano General Hospital, 4-59-16 Chuo, Nakano-ku, Tokyo 164-8607, Japan.

Received: 14 January 2021 Accepted: 20 April 2021

Published online: 12 June 2021

\section{References}

1. Todani $T$, Tabuchi $K$, Watanabe $Y$, Kobayashi T. Carcinoma arising in the wall of congenital bile cysts. Cancer. 1979;44:1134-41. https://doi.org/10. 1002/1097-0142(197909)44:3<1134::AID-CNCR2820440350>3.0.CO;2-T.

2. Kamisawa T, Kuruma S, Chiba K. Congenital biliary dilatation and pancreaticobiliary maljunction. J Jpn Gastroenterol. 2016;113:1991-7. https://doi. org/10.11405/nisshoshi.113.1991.

3. Watanabe $Y$, Toki A, Todani T. Bile duct cancer developed after cyst excision for choledochal cyst. J Hepatobiliary Pancreat Surg. 1999;6:207-12. https://doi.org/10.1007/s005340050108.

4. Oshiro Y, Gen R, Hashimoto S, Oda T, Sato T, Ohkohchi N. Neuroendocrine carcinoma of the extrahepatic bile duct: a case report. World J Gastroenterol. 2016;22:6960-4. https://doi.org/10.3748/wjg.v22.i30.6960.

5. Takahashi K, Sasaki R, Oshiro Y, Fukunaga K, Oda T, Ohkohchi N. Welldifferentiated endocrine carcinoma originating from the bile duct in association with a congenital choledochal cyst. Int Surg. 2012;97:315-20. https://doi.org/10.9738/CC152.1.

6. Tonnhofer U, Balassy C, Reck CA, Koller A, Horcher E. Neuroendocrine tumor of the common hepatic duct, mimicking a choledochal cyst in a 6-year-old child. J Pediatr Surg. 2009;44:e23-5. https://doi.org/10.1016/j. jpedsurg.2009.03.030

7. Maemura K, Natsugoe S, Takao S. Molecular mechanism of cholangiocarcinoma carcinogenesis. J Hepatobiliary Pancreat Sci. 2014;21:754-60. https://doi.org/10.1002/jhbp.126.

8. Todani T, Watanabe Y, Urushihara N, Morotomi Y, Maeba T. Choledochal cyst, pancreatobiliary malunion, and cancer. J Hepatobiliary Pancreat Surg. 1994;1:247-51. https://doi.org/10.1007/BF02391075.

9. Tsuchida A, Itoi T. Carcinogenesis and chemoprevention of biliary tract cancer in pancreaticobiliary maljunction. World J Gastrointest Oncol. 2010;2:130-5. https://doi.org/10.4251/wjgo.v2.i3.130.

10. Funabiki T, Matsubara T, Miyakawa S, Ishihara S. Pancreaticobiliary maljunction and carcinogenesis to biliary and pancreatic malignancy. Langenbecks Arch Surg. 2009;394:159-69. https://doi.org/10.1007/ s00423-008-0336-0.

11. Rindi G, Klimstra DS, Abedi-Ardekani B, Asa SL, Bosman FT, Brambilla E, et al. A common classification framework for neuroendocrine neoplasms: an International Agency for Research on Cancer (IARC) and World 
Health Organization (WHO) expert consensus proposal. Mod Pathol. 2018;31:1770-86. https://doi.org/10.1038/s41379-018-0110-y.

12. Yadav R, Jain D, Mathur SR, lyer VK. Cytomorphology of neuroendocrine tumors of the gallbladder. Cytopathology. 2016;27:97-102. https://doi. org/10.1111/cyt.12239.

13. Sciarra A, Missiaglia E, Trimech M, Melloul E, Brouland JP, Sempoux C, et al. Gallbladder mixed neuroendocrine-non-neuroendocrine neoplasm (MiNEN) arising in intracholecystic papillary neoplasm: clinicopathologic and molecular analysis of a case and review of the literature. Endocr Pathol. 2020;31:84-93. https://doi.org/10.1007/s12022-020-09605-6.

14. Kamisawa T, Honda G, Kurata M, Tokura M, Tsuruta K. Pancreatobiliary disorders associated with pancreaticobiliary maljunction. Dig Surg. 2010;27:100-4. https://doi.org/10.1159/000286502.

15. Kamisawa T, Kuruma S, Tabata T, Chiba K, Iwasaki S, Koizumi S, et al. Pancreaticobiliary maljunction and biliary cancer. J Gastroenterol. 2015;50:273-9. https://doi.org/10.1007/s00535-014-1015-2.

16. Albores-Saavedra J, Batich K, Hossain S, Henson DE, Schwartz AM. Carcinoid tumors and small-cell carcinomas of the gallbladder and extrahepatic bile ducts: a comparative study based on 221 cases from the surveillance, epidemiology, and end results program. Ann Diagn Pathol. 2009;13:378-83. https://doi.org/10.1016/j.anndiagpath.2009.08.002.

17. Zhang L, Wan D, Bao L, Chen Q, Xie H, Xu S, et al. Neuroendocrine carcinoma in the extrahepatic biliary tract: a case report and literature review. Medicine (Baltimore). 2018;97:e1 1487. https://doi.org/10.1097/md.00000 00000011487.

18. Terashima T, Morizane C, Hiraoka N, Tsuda H, Tamura T, Shimada Y, et al. Comparison of chemotherapeutic treatment outcomes of advanced extrapulmonary neuroendocrine carcinomas and advanced small-cell lung carcinoma. Neuroendocrinology. 2012;96:324-32. https://doi.org/10, 1159/000338794.

19. Strosberg J, Mizuno N, Doi T, Grande E, Delord JP, Shapira-Frommer $R$, et al. Efficacy and safety of pembrolizumab in previously treated advanced neuroendocrine tumors: results from the Phase II KEYNOTE-158 Study. Clin Cancer Res. 2020;26:2124-30. https://doi.org/10.1158/10780432.CCR-19-3014.

20. Yao JC, Fazio N, Singh S, Buzzoni R, Carnaghi C, Wolin E, et al. Advanced Neuroendocrine Tumours, Fourth Trial (RADIANT-4) Study
Group,Everolimus for the treatment of advanced, non-functional neuroendocrine tumours of the lung or gastrointestinal tract (RADIANT-4): a randomised, placebo-controlled, phase 3 study. Lancet. 2016;387:968-77. https://doi.org/10.1016/S0140-6736(15)00817-X.

21. Yao JC, Strosberg J, Fazio N, Pavel ME, Ruszniewski P, Bergsland E, et al. Activity \& safety of spartalizumab (PDR001) in patients (pts) with advanced neuroendocrine tumors (NET) of pancreatic (Pan), gastrointestinal (Gl), or thoracic ( $T$ ) origin, \& gastroenteropancreatic neuroendocrine carcinoma (GEP NEC) who have progressed on prior treatment (Tx). Ann Oncol. 2018;29:467-8. https://doi.org/10.1093/annonc/mdy293.001.

22. Vijayvergia N, Dasari A, Deng M, Litwin S, Al-Toubah T, Alpaugh RK, et al. Pembrolizumab monotherapy in patients with previously treated metastatic high-grade neuroendocrine neoplasms: joint analysis of two prospective, non-randomised trials. Br J Cancer. 2020;122:1309-14. https://doi.org/10.1038/s41416-020-0775-0.

23. Mehnert JM, Bergsland E, O'Neil BH, Santoro A, Schellens JHM, Cohen $\mathrm{RB}$, et al. Pembrolizumab for the treatment of programmed death-ligand 1-positive advanced carcinoid or pancreatic neuroendocrine tumors: results from the KEYNOTE-028 study. Cancer. 2020;126:3021-30. https:// doi.org/10.1002/cncr.32883.

24. Capdevila J, Teule A, López C, García-Carbonero R, Benavent M, Custodio A, et al. 11570 A multi-cohort phase II study of durvalumab plus tremelimumab for the treatment of patients (pts) with advanced neuroendocrine neoplasms (NENs) of gastroenteropancreatic or lung origin: the DUNE trial (GETNE 1601). Ann Oncol. 2020;31:770-1. https://doi.org/10. 1016/j.annonc.2020.08.1370.

25. Klein O, Kee D, Markman B, Michael M, Underhill C, Carlino MS, et al. Immunotherapy of ipilimumab and nivolumab in patients with advanced neuroendocrine tumors: a subgroup analysis of the CA209-538 clinical trial for rare cancers. Clin Cancer Res. 2020;26:4454-9. https://doi.org/10. 1158/1078-0432.CCR-20-0621

\section{Publisher's note}

Springer Nature remains neutral with regard to jurisdictional claims in published maps and institutional affiliations.

Ready to submit your research? Choose BMC and benefit from:

- fast, convenient online submission

- thorough peer review by experienced researchers in your field

- rapid publication on acceptance

- support for research data, including large and complex data types

- gold Open Access which fosters wider collaboration and increased citations

- maximum visibility for your research: over 100M website views per year

At BMC, research is always in progress.

Learn more biomedcentral.com/submissions 